\title{
System Failure Recognition and Identification by Analyzing Syslog and SNS Data: Applying Big Data Analysis to Network Operations
}

\author{
D.Vimala, P.Nandhini, R. Elankavi
}

\begin{abstract}
We present two major information examination strategies for diagnosing the reasons for system disappointments and for identifying system disappointments early. Syslogs contain log information created by the framework. We dissected syslogs what's more, prevailing with regards to distinguishing the reason for a system disappointment via consequently learning more than 100 million logs without requiring any past learning of log information. Investigation of the information of an interpersonal interaction benefit (in particular, Twitter) empowered us to recognize conceivable system disappointments by extricating system disappointment related tweets, which represent under $1 \%$ of all tweets, continuously and with high exactness.
\end{abstract}

Keywords: big data, syslog, network failure detection .

\section{INTRODUCTION}

Web convention (IP) systems comprise of numerous sorts of hardware from various merchants. These systems are winding up noticeably significantly more unpredictable in light of the fact that of the expanding interest for new and diverse applications[1],[3],[5]. Also, large portions of these applications are given by various system administrators and gadgets, also, this makes it extremely hard to analyze organize disappointments when they happen. Thus, it is exceptionally critical to create techniques to productively recognize organize disappointments and analyze their causes. In this article, we present two strategies for breaking down information from syslogs and from a person to person communication benefit (SNS) to accomplish early system disappointment recognition and to analyze the reason for the system disappointment that current working techniques can't address. [2 ],[4],[6]

Revised Manuscript Received on July 22, 2019.

D.Vimala, Department of CSE, Bharath Institute of Higher Education and Research, Chennai, Tamilnadu, India.Email:vimalamuthu3@gmail.com

P.Nandhini, Department of CSE, Bharath Institute of Higher Education and Research, Chennai, Tamilnadu, India. Email:pnandhinisuresh@gmail.com

R. Elankavi, Department of CSE, Bharath Institute of Higher Education and Research, Chennai, Tamilnadu, India. Email:kavirajcse@gmail.com

\section{LOG DATA ANALYSIS}

Arrange administrators screen different sorts of data for example, trap data from system components, organize activity, CPU (focal preparing unit)/memory utility information, and syslog information[7],[ 9] ,[11]. Specifically, the syslog information of system components, for example, switches, switches, and RADIUS (Remote Access Dial In Client Service) servers incorporate gritty and exact data for investigating and checking the wellbeing of systems when arrangements change. Be that as it may, breaking down log information has turned out to be extremely troublesome for the accompanying reasons:

(i)There are different sorts of logs, which list messages with low or high seriousness. What's more, the increment in the quantity of system components implies there is an enormous volume of complex log information, and it is along these lines important to extricate data precisely and productively all together to complete investigating and preventive maintenance.out to be extremely troublesome for the accompanying reasons[8],[10], [12]

(i)There are different sorts of logs, which list messages with low or high seriousness. What's more, the increment in the quantity of system components implies there is an enormous volume of complex log information, and it is along these lines important to extricate data precisely and productively all together to complete investigating and preventive maintenance

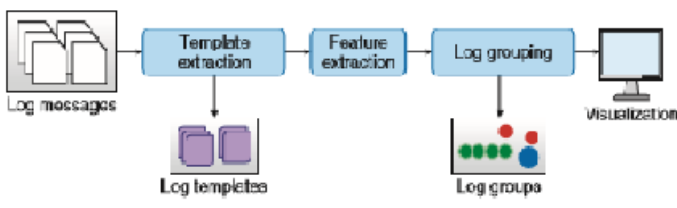

Fig. 1. Flowchart for visualization of logs.

Fig. 2. Conceptual image of log template extraction.

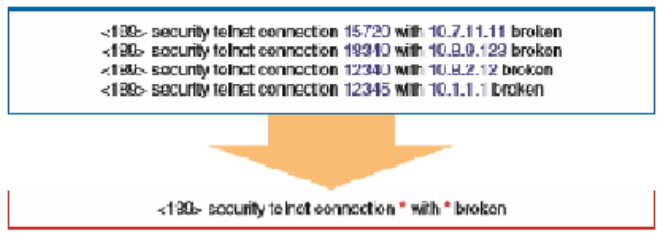

(ii) The log organize relies on upon every seller or administration. Subsequently, understanding the significance of each $\log$ message requires profound area information of each 
configuration. To defeat these issues, we have built up a method to dissect syslogs that includes consequently extricating the connections or variations from the norm from $\log$ messages utilizing machine-learning strategies without depending on any area information about the design or the seller of log information (Fig. 1). This examination system comprises of four stages: log layout extraction, log include extraction, $\log$ gathering, and perception of irregular occasions.

\section{LOG TEMPLATE EXTRACTION}

Log messages contain various parameters such as IP address, host name, and PID (process identification). Because parameter words are very rare, log messages with unique parameters may never appear twice even though the events the messages signify are the same. Therefore, we automatically extract a primary template from all log messages based on the observation that parameter words appear infrequently in comparison with template words in the other positions (Fig. 2). The log template enables us to easily correlate log messages[13], [15],[17]

\section{FEATURE EXTRACTION}

As mentioned before, the vendor's severity of a log message is not necessarily reliable because it is not directly related to the actual network abnormality. Therefore, we need to quantify the abnormality and normality of logs without considering the severity of the message and without requiring any domain knowledge[14],[ 16], [18]. For example, firewall logs and link down/ up logs related to users' connect/disconnect events contain very common messages and can be considered. Also, the logs generated by cron* jobs or in regular monitoring are not as frequent but are generated periodically on a daily basis. Therefore we define the frequency and periodicity features for log messages.

\section{VISUALISATION}

Ordinarily, organize administrators don't utilize a one-line log message, yet rather, a gathering of logs. For instance, a switch reboot occasion incites different logs, which shows that different procedures begin in the meantime.Along these lines, we have to gathering them as far as their cooccurrence. Gathering logs lessens the volume of logs and helps administrators comprehend the logs. For log gathering, we utilize the machine learning system known as non-negative framework factorization (NMF) by changing over info log information into a network (Fig. 3).

Fig. 5. Example of log graph (one week's syslog data).

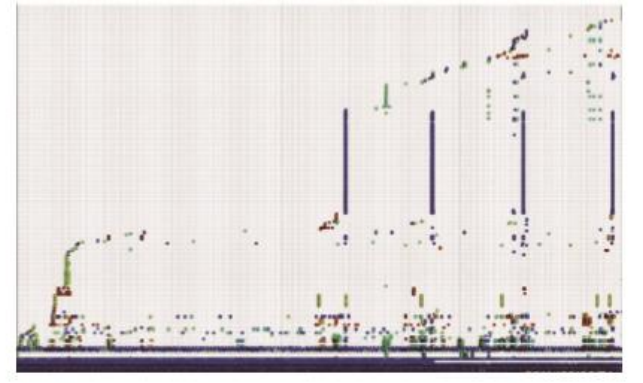

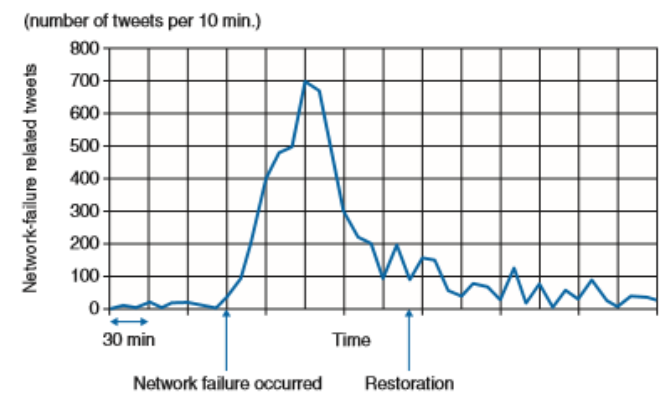

Fig. 6. Time series of tweet counts related to an actual network failure

\section{LOG GROUPING}

Ordinarily, arrange administrators don't utilize a one-line log message, but instead, a gathering of logs. For instance,a switch reboot occasion prompts numerous logs, which shows that different procedures begin in the meantime. Subsequently, we have to gathering them as far as their cooccurrence[19],[21],[23]. Gathering logs lessens the volume of logs and helps administrators comprehend the logs. For log gathering, we utilize the machine learning procedure known as non-negative grid factorization (NMF) by changing over information log information into a lattice (Fig. 3).

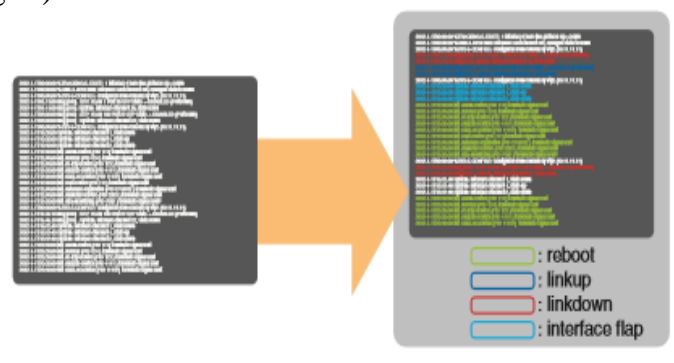

\section{TWITTER ANALYSIS}

In this progression of the investigation, $\log$ information are communicated as a diagram. A calculated picture of log perception is appeared in Fig. 4, and a case of a log diagram is aappeared in Fig. 5. In both figures, the even hub speaks to time, and the vertical pivot speaks to the format or log bunches specified before. Each point in the diagram speaks to the event of each log format or log assemble at each time. Hosts are recognized by their diverse hues and examples in this illustration[20],[22], [24]. The request of log layouts or $\log$ bunches on Arrange administrators can screen organize hardware by utilizing observing innovation, for example, SNMP (basic system administration convention). Despite the fact that they can distinguish equipment disappointments, it is troublesome for organize administrators to recognize disappointments brought about by programming bugs or to distinguish quality weakening due to clog. Thusly, a few cases end up plainly quiet disappointments, which can't be distinguished by system administrators. We have concentrated an approach to screen an informal communication benefit (SNS), to be specific, Twitter [2], to find issues influencing endorsers. For instance, we can see a surge in tweets about system disappointments when a system 
disappointment happens, as appeared in Fig. 6. We created a framework to screen Twitter progressively by checking for surges in these sorts of tweets[25],[27],[29]

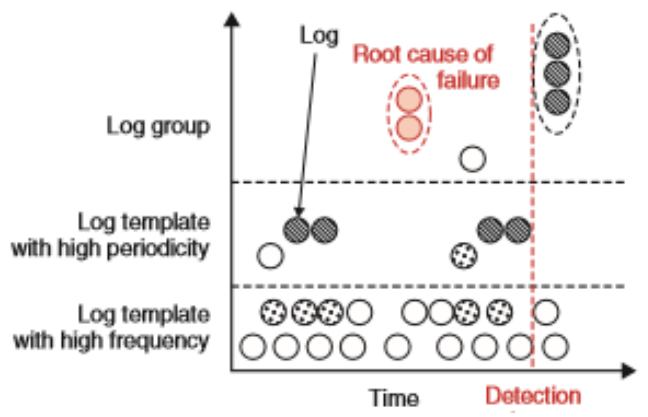

\section{METHOD TO EXTRACT ONLY NETWORK -FAILURE RELATED TWEETS}

We found in our examination that catchphrase coordinating, a conventional approach to pursuit tweets, was not adequate for mechanized observing on the grounds that it brought about numerous false positives. This happens when the tweets contained the watchwords, however the tweets were most certainly not identified with issues with the system. For instance, if we look utilizing the watchwords call and drop, we may get tweets, for example, "I dropped my telephone in the can so I can't call or content". Since watchwords, for example, call what's more, drop are not organize particular words, catchphrase coordinating may prompt a ton of false positive tweets that contain the watchwords however not the point of the arrange issue. The system disappointment location engineering is appeared in Fig

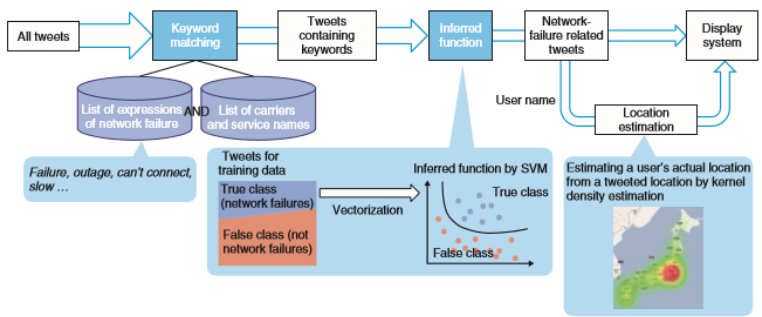

Fig. 7. Framework of network-failure detection system using Twitter.

We utilize regulated adapting, specifically, SVM (bolster vector machine), to stifle the false positives. Managed learning utilizes an informational collection of preparing cases. Each preparation illustration comprises of a couple of the content of a tweet and a mark demonstrating whether the tweet is identified with a system disappointment[38],[40]. An administered learning calculation dissects the preparation information and produces an induced capacity to gap tweets into those that are identified with system disappointments and those that are most certainly not. In our approach, each tweet is interpreted into a vector by utilizing the pack of-words strategy, which is a customary strategy in archive arrangement. This technique can be relied upon to stifle the false positives by factually considering all words showing up in one tweet. We assessed the viability of our strategy by applying it to a whole year of Twitter information[26],[28],[30]. Six system disappointments were accounted for by a system transporter in that period. We assessed the system disappointment discovery framework by tallying the quantity of tweets that were grouped by our technique. At the point when the tally surpassed a specific edge, we viewed it as an alarm of a system disappointment[31],[33],[35]

. We additionally utilized the watchword coordinating strategy for correlation. Both techniques distinguished the 6 real system disappointments. Nonetheless, the catchphrase just strategy likewise erroneously recognized 94 occasions, though the machine-learning strategy smothered all of those and had just 6 false detections.

\section{METHOD TO DETERMINE THE LOCATION OF TWEETERSS}

Twitter has a capacity to join the client's area by GPS (Global Positioning System) information, however most clients pick not to select into this capacity. Consequently, we have to gauge the area of Twitter clients who composed the system disappointment related tweets. A few reviews have utilized the predisposition of a circulation of words, which fundamentally includes tongue qualities, to assess a client's area[32],[34],[36]. Be that as it may, these reviews evaluate an unpleasant granularity of zones, for example, the Kanto area with a mistake of around $150 \mathrm{~km}$ and don't meet our necessity, which is to accomplish at any rate prefecture-level area (a mistake of under $50 \mathrm{~km}$ ). Along these lines, we concentrated a high-precision area estimation strategy that utilizations gazetteer data, which incorporates the sets of a geographic name and its organizes. While most tweets don't contain GPS data, many tweets contain a geographic name. In spite of the fact that clients may tweet the geographic names of puts other than where they are really found, the covered areas of a significant number of their tweets will make it conceivable to assess their area on the grounds that Twitter is an administration for clients to post what they are doing. We utilized the part thickness estimation technique to cover the tweets of individual tweeters[37],[39],[41]. We assessed the estimation mistake of clients whose areas were known and found that the estimation mistake was under 50 $\mathrm{km}$ for $66 \%$ of those clients. Moreover, the estimation mistake was under $25 \mathrm{~km}$ for half of all clients, which showed that our technique was powerful.

\section{CONCLUSION}

We introduced a big-data approach consisting of syslog and SNS analysis to predict or detect network failures. In cooperation with group companies, we are now evaluating the efficiency of syslog analysis using actual syslog data. We are also preparing a proposal for group companies for the use of SNS analysis as a tool for detecting silent failures 


\section{REFERENCES}

[1] Kumarave A., Rangarajan K.,Algorithm for automaton specification for exploring dynamic labyrinths,Indian Journal of Science and Technology,V-6,I-SUPPL5,PP-4554-4559,Y-2013

[2] P. Kavitha, S. Prabakaran "A Novel Hybrid Segmentation Method with Particle Swarm Optimization and Fuzzy C-Mean Based On Partitioning the Image for Detecting Lung Cancer" International Journal of Engineering and Advanced Technology (IJEAT) ISSN: 2249-8958, Volume-8 Issue-5, June 2019

[3] Kumaravel A., Meetei O.N.,An application of non-uniform cellular automata for efficient cryptography,2013 IEEE Conference on Information and Communication Technologies, ICT 2013,V-,I-,PP-1200-1205,Y-2013

[4] Kumarave A., Rangarajan K.,Routing alogrithm over semi-regular tessellations,2013 IEEE Conference on Information and Communication Technologies, ICT 2013,V-,I-,PP-1180-1184,Y-2013

[5] P. Kavitha, S. Prabakaran "Designing a Feature Vector for Statistical Texture Analysis of Brain Tumor" International Journal of Engineering and Advanced Technology (IJEAT) ISSN: 2249-8958, Volume-8 Issue-5, June 2019

[6] Dutta P., Kumaravel A.,A novel approach to trust based identification of leaders in social networks,Indian Journal of Science and Technology,V-9,I-10,PP--,Y-2016

[7] Kumaravel A., Dutta P.,Application of Pca for context selection for collaborative filtering,Middle - East Journal of Scientific Research,V-20,I-1,PP-88-93,Y-2014

[8] Kumaravel A., Rangarajan K.,Constructing an automaton for exploring dynamic labyrinths,2012 International Conference on Radar, Communication and Computing, ICRCC 2012,V-,I-,PP-161-165,Y-2012

[9] P. Kavitha, S. Prabakaran "Adaptive Bilateral Filter for Multi-Resolution in Brain Tumor Recognition" International Journal of Innovative Technology and Exploring Engineering (IJITEE) ISSN: 2278-3075, Volume-8 Issue-8 June, 2019

[10] Kumaravel A.,Comparison of two multi-classification approaches for detecting network attacks, World Applied Sciences Journal,V-27,I-11,PP-1461-1465,Y-2013

[11] Tariq J., Kumaravel A.,Construction of cellular automata over hexagonal and triangular tessellations for path planning of multi-robots,2016 IEEE International Conference on Computational Intelligence and Computing Research, ICCIC 2016,V-,I-,PP--,Y-2017

[12] Sudha M., Kumaravel A.,Analysis and measurement of wave guides using poisson method,Indonesian Journal of Electrical Engineering and Computer Science, V-8,I-2,PP-546-548,Y-2017

[13] Ayyappan G., Nalini C., Kumaravel A.,Various approaches of knowledge transfer in academic social network,International Journal of Engineering and Technology,V-,I-PP-2791-2794,Y-2017

[14] Kaliyamurthie, K.P., Sivaraman, K., Ramesh, S. Imposing patient data privacy in wireless medical sensor networks through homomorphic cryptosystems 2016, Journal of Chemical and Pharmaceutical Sciences 92

[15] Kaliyamurthie, K.P., Balasubramanian, P.C. An approach to multi secure to historical malformed documents using integer ripple transfiguration 2016 Journal of Chemical and Pharmaceutical Sciences 92.

[16] A.Sangeetha,C.Nalini,"Semantic Ranking based on keywords extractions in the web", International Journal of Engineering \& Technology, 7 (2.6) (2018) 290-292

[17] S.V.GayathiriDevi,C.Nalini,N.Kumar,"An efficient software verification using multi-layered software verification tool "International Journal of Engineering \& Technology, 7(2.21)2018 454-457

[18] C.Nalini,ShwtambariKharabe,"A Comparative Study On Different Techniques Used For Finger - Vein Authentication", International Journal Of Pure And Applied Mathematics, Volume 116 No. 82017 327-333, Issn: 1314-3395

[19] M.S. Vivekanandan and Dr. C. Rajabhushanam, "Enabling Privacy Protection and Content Assurance in Geo-Social Networks", International Journal of Innovative Research in Management, Engineering and Technology, Vol 3, Issue 4, pp. 49-55, April 2018.

[20] Dr. C. Rajabhushanam, V. Karthik, and G. Vivek, "Elasticity in Cloud Computing", International Journal of Innovative Research in Management, Engineering and Technology, Vol 3, Issue 4, pp. 104-111, April 2018.

[21] K. Rangaswamy and Dr. C. Rajabhushanamc, "CCN-Based Congestion Control Mechanism In Dynamic Networks", International Journal of Innovative Research in Management, Engineering and Technology, Vol 3, Issue 4, pp. 117-119, April 2018

[22] Kavitha, R., Nedunchelian, R., "Domain-specific Search engine optimization using healthcare ontology and a neural network backpropagation approach", 2017, Research Journal of Biotechnology, Special Issue 2:157-166

[23] Kavitha, G., Kavitha, R., "An analysis to improve throughput of high-power hubs in mobile ad hoc network", 2016, Journal of Chemical and Pharmaceutical Sciences, Vol-9, Issue-2: 361-363

[24] Kavitha, G., Kavitha, R., "Dipping interference to supplement throughput in MANET" , 2016, Journal of Chemical and Pharmaceutical Sciences, Vol-9, Issue-2: 357-360

[25] Michael, G., Chandrasekar, A.,"Leader election based malicious detection and response system in MANET using mechanism design approach", Journal of Chemical and Pharmaceutical Sciences(JCPS) Volume 9 Issue 2, April - June 2016

[26] Michael, G., Chandrasekar, A.,"Modeling of detection of camouflaging worm using epidemic dynamic model and power spectral density", Journal of Chemical and Pharmaceutical Sciences(JCPS) Volume 9 Issue 2, April - June 2016

[27] Pothumani, S., Sriram, M., Sridhar, J., Arul Selvan, G., Secure mobile agents communication on intranet,Journal of Chemical and Pharmaceutical Sciences, volume 9, Issue 3, Pg No S32-S35, 2016

[28] Pothumani, S., Sriram, M., Sridhar , Various schemes for database encryption-a survey, Journal of Chemical and Pharmaceutical Sciences, volume 9, Issue 3, Pg NoS103-S106, 2016

[29] Pothumani, S., Sriram, M., Sridhar, A novel economic framework for cloud and grid computing, Journal of Chemical and Pharmaceutical Sciences, volume 9, Issue 3, Pg No S29-S31, 2016

[30] Priya, N., Sridhar, J., Sriram, M. "Ecommerce Transaction Security Challenges and Prevention Methods- New Approach" 2016 ,Journal of Chemical and Pharmaceutical Sciences, JCPS Volume 9 Issue 3.page no:S66-S68 .

[31] Priya, N.,Sridhar,J.,Sriram, M.“Vehicular cloud computing security issues and solutions" Journal of Chemical and Pharmaceutical Sciences(JCPS) Volume 9 Issue 2, April - June 2016

[32] Priya, N., Sridhar, J., Sriram, M. "Mobile large data storage security in cloud computing environment-a new approach" JCPS Volume 9 Issue 2. April - June 2016

[33] Anuradha.C, Khanna.V, "Improving network performance and security in WSN using decentralized hypothesis testing "Journal of Chemical and Pharmaceutical Sciences(JCPS) Volume 9 Issue 2, April - June 2016.

[34] Anuradha.C, Khanna.V, "A novel gsm based control for e-devices" Journal of Chemical and Pharmaceutical Sciences(JCPS) Volume 9 Issue 2, April - June 2016

[35] Anuradha.C, Khanna.V, "Secured privacy preserving sharing and data integration in mobile web environments " Journal of Chemical and Pharmaceutical Sciences(JCPS) Volume 9 Issue 2, April - June 2016.

[36] Sundarraj, B., Kaliyamurthie, K.P. Social network analysis for decisive the ultimate classification from the ensemble to boost accuracy rates 2016 International Journal of Pharmacy and Technology 8

[37] Sundarraj, B., Kaliyamurthie, K.P. A content-based spam filtering approach victimisation artificial neural networks 2016 International Journal of Pharmacy and Technology 83 .

[38] Sundarraj, B., Kaliyamurthie, K.P. Remote sensing imaging for satellite image segmentation 2016 International Journal of Pharmacy and Technology $8 \quad 3$

[39] Sivaraman, K., Senthil, M. Intuitive driver proxy control using artificial intelligence 2016 International Journal of Pharmacy and Technology $8 \quad 4$.

[40] Sivaraman, K., Kaliyamurthie, K.P. Cloud computing in mobile technology 2016 Journal of Chemical and Pharmaceutical Sciences 92.

[41] Sivaraman, K., Khanna, V. Implementation of an extension for browser to detect vulnerable elements on web pages and avoid click jacking 2016 Journal of Chemical and Pharmaceutical Sciences 92. 


\section{AUTHORS PROFILE}

DVimala Assistant Professor, Department of Computer Science \& Engineering, Bharath Institute of Higher Education and Research, Chennai, India

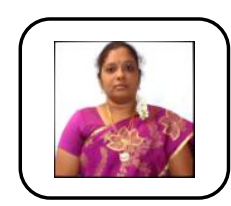

P.Nandhini Assistant Professor, Department of Computer Science \& Engineering, Bharath Institute of Higher Education and Research, Chennai, India

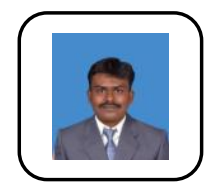

R.Elankavi Assistant Professor, Department of Computer Science \& Engineering, Bharath Institute of Higher Education and Research, Chennai, India 